\title{
Replication of reported genetic associations of PADI4, FCRL3, SLC22A4 and RUNX1 genes with rheumatoid arthritis: results of an independent Japanese population and evidence from meta-analysis of East Asian studies
}

\author{
Yoichiro Takata $\cdot$ Hiroshi Inoue $\cdot$ Aya Sato $\cdot$ Kazue Tsugawa $\cdot$ \\ Katsutoshi Miyatake - Daisuke Hamada - Fumio Shinomiya - Shunji Nakano • \\ Natsuo Yasui · Toshihito Tanahashi · Mitsuo Itakura \\ Received: 30 October 2007/Accepted: 19 November 2007/Published online: 18 December 2007 \\ (C) The Japan Society of Human Genetics and Springer 2007
}

\begin{abstract}
We conducted population-based association tests for the four selected SNPs (rs2240340/padi4_94, rs7528684/fcrl3_3, rs3792876/slc2F2 and rs2268277/ runxl) previously reported to be associated with rheumatoid arthritis (RA). The study population consisted of 950 unrelated Japanese subjects with RA and 507 controls, none of whom had previously been tested for these variants. Only the SNP rs2240340/padi4_94 was modestly associated with RA [allele odds ratio (OR) 1.22, 95\% confidence interval (CI) 1.04-1.43, $P=0.012]$. The most significant association effect was found for genotype contrast between minor and major allele homozygotes (OR $1.53,95 \%$ CI $1.10-2.12, P=0.010)$. No other SNPs showed a statistically significant association with RA in our population. Meta-analysis of published studies and our new data confirmed a highly significant association between PADI4 gene SNPs and increased risk of RA in East Asian populations (allele fixed-effects summary OR $1.31,95 \%$ CI $1.22-1.41, P<0.0001)$. We found some evidence for an association of either rs7528684/fcrl3_3 or rs3792876/slc2F2 with RA; however, because the
\end{abstract}

Electronic supplementary material The online version of this article (doi:10.1007/s10038-007-0232-4) contains supplementary material, which is available to authorized users.

Y. Takata $\cdot$ H. Inoue $(\bowtie) \cdot A$. Sato $\cdot$ K. Tsugawa

T. Tanahashi $\cdot$ M. Itakura

Division of Genetic Information, Institute for Genome Research,

The University of Tokushima, 3-18-15 Kuramoto-cho,

Tokushima, Tokushima 770-8503, Japan

e-mail: hinoue@genome.tokushima-u.ac.jp

Y. Takata $\cdot$ K. Miyatake $\cdot$ D. Hamada $\cdot$ F. Shinomiya

S. Nakano $\cdot$ N. Yasui

Department of Orthopedics, Institute of Health Biosciences,

The University of Tokushima, Tokushima, Japan magnitudes of effects were apparently much weaker than those reported in the initial positive reports, and there were substantial levels of inter-study OR heterogeneity, we concluded that additional studies are needed to fully understand the present results.

Keywords Rheumatoid arthritis - PADI4 - FCRL3 . SLC22A4 - RUNX1 - Single nucleotide polymorphisms . Genetic association study $\cdot$ Meta-analysis

\section{Introduction}

Rheumatoid arthritis (RA) is a common autoimmune/ inflammatory condition, characterized by chronic, destructive and debilitating arthritis (Harris 1990). The etiology of RA is still largely unknown, but there is thought to be a major genetic influence. The importance of the human leukocyte antigen (HLA)-DRBI gene has been confirmed in nearly every population: i.e., carriage of certain alleles, collectively termed "shared epitope (SE)," confers a two- to threefold increased risk of RA (Reveille 1998). Non-HLA genes are also thought to be involved in RA susceptibility. However, definitive identification of the responsible gene(s) has been challenging. Recently, the genetic association between a non-synonymous SNP in the PTPN22 gene (R620W; rs2476601) and the development of RA in Europeans has been widely replicated (Begovich et al. 2004; Gregersen et al. 2006). It is noteworthy that this variant appears not to be present or is extremely rare in Asian populations, and haplotypic analysis of other PTPN22 SNPs has revealed no clear evidence for an association (Ikari et al. 2006a), suggesting etiological complexity and ethnic heterogeneity of RA (Mori et al. 2005). More recently, association studies have identified 
four different, highly interesting genes, PADI4, FCRL3, SLC22A4 and RUNX1, with convincing evidence of associations with RA in the Japanese population (Suzuki et al. 2003; Kochi et al. 2005; Tokuhiro et al. 2003).

The PADI4 gene encodes the type IV peptidylarginine deiminase (PADI) enzyme, one of five known human PADI isoforms. PADI activity appears to be implicated in the generation of anti-cyclic citrullinated peptide (CCP) antibody, which is highly specific to patients with RA. It has also been demonstrated that, in RA patients, the presence of the HLA-DRB1 SE alleles was exclusively associated with anti-CCP antibody seropositivity (de Vries et al. 2005). Thus, PADI4 is an excellent candidate gene for RA. Recently, Suzuki et al. (2003) reported a strong genetic association between the PADI4 SNPs and RA in a Japanese population. The highest association was observed for a SNP located in intron 3 of PADI4 (padi4_94; $P=0.000008)$. Further analyses revealed the susceptible haplotype marked by disease-associated SNPs to be functional, affecting the stability of PADI4 mRNA, and its frequency was associated with the development of antiCCP antibody-positive RA. The genetic association between PADI4 and RA was replicated in another Japanese group (Ikari et al. 2005) and in a Korean population (Kang et al. 2006), although many studies of Caucasian subjects yielded conflicting findings (Barton et al. 2005a; Harney et al. 2005; Martinez et al. 2005; Plenge et al. 2005; Hoppe et al. 2006). Recent meta-analyses of PADI4 SNPs, however, hinted at an association in European RA patients (Iwamoto et al. 2006; Lee et al. 2007).

The human FCRL3 gene maps to chromosome 1q21-23, the genomic region encompassing a gene cluster of Fc-like receptors (FCRL1-5) and a family of Fc $\gamma$ receptor II/III (FCGR2-3) genes. This locus has previously been implicated in susceptibility to several autoimmune diseases. In a large-scale association mapping study in a Japanese population, four FCRL3 SNPs were found to be strongly associated with RA (Kochi et al. 2005). The SNP fcrl3_3, located at position -169 , relative to the transcriptional start site of FCRL3, showed the most significant association with RA (maximum OR 2.15, $P=0.00000085$, under a recessive model), association of which was replicated in the same study in another cohort of RA patients. In addition, significant genetic associations with the development of systemic lupus erythematosus and autoimmune thyroid disease were also found. Among RA patients, the susceptibility allele of $f c r l 3 \_3$ was linked to both elevated serum rheumatoid factor (RF) and anti-CCP positivity. This SNP was found to occur within a consensus binding site for the transcription factor $\mathrm{NF}-\kappa \mathrm{B}$, resulting in a functional alteration of the NF- $\kappa \mathrm{B}$ binding as well as altered FCRL3 gene transcription. The association between $f c r l 3 \_3$ and RA was replicated in an independent Japanese case-control sample collection in a separate study (Ikari et al. 2006b), while a large study of Korean subjects failed to demonstrate a significant effect (Choi et al. 2006). Several studies have assessed the role of $f$ crl3_3 in the development of RA in Caucasians, and many failed to replicate the earlier results (Martinez et al. 2006a; Eyre et al. 2006; Newman et al. 2006; Thabet et al. 2007). A recent meta-analysis involving more than 10,000 white subjects provided no evidence of association (Begovich et al. 2007).

Through an association study and fine mapping of the candidate chromosome region on 5q31, Tokuhiro et al. (2003) found SNPs within the SLC22A4 gene encoding the cation transporter OCTN1 to be strongly associated with RA in a Japanese population. The SNP slc $2 F 1$ showed the most significant effect (maximum OR 1.98, $P=0.000034$, under a recessive model). Expression of SLC22A4 was revealed to be specific in hematological and immunological tissues, and was also observed in the synovial tissues of RA patients. An intron $1 \mathrm{SNP}$ of $S L C 22 A 4$, slc $2 F 2$, which was in very strong linkage disequilibrium (LD) with slc $2 F 1$ ( $\triangle$ or $\left.r^{2}>0.97\right)$ and occurred within a putative RUNX1 binding site, was shown to affect the transcriptional efficiency of SLC22A4. RUNX1 is a transcription factor that belongs to the runt-domain gene family, and is known to be important for hematopoiesis and osteogenesis. Intriguingly, a genetic variant of the RUNX1 gene itself was also found to be implicated in RA susceptibility, where an intronic SNP, designated runxl, was strongly associated with RA risk (maximum OR 1.48, $P=0.00035$, under a dominant model) (Tokuhiro et al. 2003). To date, the findings of Tokuhiro and colleagues have not been replicated in either Japanese or Caucasian populations (Kuwahara et al. 2005; Barton et al. 2005b; Newman et al. 2005; Martinez et al. 2006b; Orozco et al. 2006), while it is interesting to note that, in Caucasian populations, a nonsynonymous substitution $(1672 \mathrm{C}>T$; rs1050152) causing an amino-acid change (L503F) in the SLC22A4 was proposed as a potential causal variant for Crohn's disease, a chronic inflammatory bowel disease with immunologically mediated processes (Fisher et al. 2006).

In the development of RA, as in other complex diseases, individual effect sizes of non- $H L A$ susceptibility genes are likely to be modest (ORs generally in the range of 1.2-1.5), making it difficult to detect or confirm associations unless thousands of subjects are assessed. Recent studies showing inconsistencies among association results also highlight the importance of accounting for ethnic differences in the pursuit of a real connection between gene(s) and RA. The above-mentioned four genes were initially identified in the Japanese populations as being strongly associated with susceptibility to RA; however, there also appears to be an inconsistency within the same ethnic background. Thus, further examination of additional population samples, 
either in more individuals per particular racial/ethnic group or in distinct populations having different genetic backgrounds, is still needed to clarify these genetic associations and evaluate possible mechanism(s) of disease susceptibility. In this study, we first undertook a case-control association analysis attempting to replicate previously identified associations in a completely independent Japanese population, consisting of 1,457 subjects (950 RA cases and 507 controls). In addition, we performed a metaanalysis using the present data and those from previously published studies, focusing on East Asian populations.

\section{Subjects and methods}

\section{Study subjects}

This study was conducted in accordance with the tenets of the Declaration of Helsinki and approved by the Ethics Committee for Human Genome and Gene Research at the University of Tokushima. Written informed consent was obtained from all participants prior to enrollment in the study. A total of 950 unrelated Japanese patients with RA $[79.1 \%$ females; mean \pm SD (standard deviation) age at enrollment $61.8 \pm 12.5$ years, mean $\pm \mathrm{SD}$ age at $\mathrm{RA}$ diagnosis $49.0 \pm 14.9$ years] were recruited through the hospital clinic at Tokushima University and its affiliates. Detailed information on patients and control subjects was previously described [Hamada et al. 2005; Takata et al. 2007; see also Electronic supplementary material (ESM) Table 1]. All patients satisfied the revised criteria of the American College of Rheumatology (Arnett et al. 1988), with a minimum disease duration of 3 years. Five hundred and seven unrelated healthy controls $(74.6 \%$ females; mean \pm SD age at enrollment $39.8 \pm 16.9$ years) were mostly employees of the University of Tokushima and related hospitals. Our previous study (Takata et al. 2007) included a total of 443 DNA samples, derived from unrelated volunteers and established by the Pharma SNP consortium (PSC) (Kamatani et al. 2004), which were excluded from the current study because some samples could possibly have been used in recent genetic association studies by other investigators (Drs. K. Ikari and N. Kamatani, personal communication). Blood specimens were collected from all subjects, and genomic DNA was extracted from peripheral blood leukocytes according to standard methods.

\section{Selection and genotyping of SNPs}

Four SNPs, rs2240340/padi4_94, rs7528684/fcrl3_3, rs3792876/slc2F2 and rs2268277/runxl, were selected for investigation because, on single-locus analyses, they had previously been shown to be strongly associated with RA in the Japanese population. The general information on the selected SNPs is summarized in ESM Table 2. All SNPs were genotyped using the TaqMan allelic discrimination assay with allele-specific fluorescent MGB probes, obtained from Applied Biosystems (Foster City, CA). The reaction was conducted with a TaqMan Universal Master Mix buffer (Applied Biosystems), with primer concentrations of $900 \mathrm{nM}$ and MGB-probe concentrations of $200 \mathrm{nM}$, in a total reaction volume of $4 \mu \mathrm{l}$. Five nanograms of genomic DNA were used as a template. After the reaction, 384-well assay plates were transferred to ABI PRISM 7900HT instruments (Applied Biosystems), and the fluorescence intensity in each well was read. Fluorescence data were first analyzed by automated allele-calling software of the instrument (SDS version 2.1) and were then independently reviewed by two experienced operators (Y.T. and A.S.). Our high-throughput genotyping was performed satisfactorily, and the overall genotyping success rate was more than $99 \%$.

\section{Statistical analysis}

For each SNP, Hardy-Weinberg equilibrium (HWE) was assessed in the case and control groups separately, using the exact test (Wigginton et al. 2005). Allelic frequencies of the SNPs in the case and control groups were compared using a $\chi^{2}$ test (allele 1 [common] vs. allele 2 [minor]). Analyses were also performed under various types of genetic contrasts including the contrast of homozygotes (genotype 11 vs. 22$)$, and the dominant $(11$ vs. $[12+22])$ and recessive $[(11+12)$ vs. 22$]$ models. In addition, Armitage's trend test, which takes into account the individuals' genotypes rather than just alleles (Sasieni 1997), was performed using the DeFinetti program provided as an online source (http://ihg.gsf.de/cgi-bin/hw/hwa1.pl). The significance level for statistical tests was set at 0.05 . Corrections for multiple comparisons have not been made, since all the SNPs were selected from highly plausible candidate genes previously reported as playing a role in RA, and were potentially functional variants, providing a priori hypotheses for their association. The crude odds ratios (ORs), their 95\% confidence intervals (CIs) and their corresponding $P$ values were calculated. Logistic regression models were used to calculate adjusted ORs, controlling for age and sex as covariables. All data management and statistical computations were performed using SNPAlyze Pro software (version 5.1; Dynacom, Yokohama, Japan) and SPSS for Windows (version 12.0; SPSS Inc., Tokyo, Japan). Statistical power to detect an association was determined with the PS power and sample-size program (available at http://www.mc.vanderbilt.edu/prevmed/ps). 
For the meta-analysis, we performed an NCBI PubMed literature search (http://www.ncbi.nlm.nih.gov/sites/entrez/), from the first publications of each gene up to 28 September 2007, using the search terms rheumatoid arthritis, gene, association, single nucleotide polymorphisms, FCRL3, PADI4, SLC22A4, OCTN1 and RUNX1. Once articles had been collected, bibliographies were further searched manually for additional references. Data were extracted using standardized forms. If incomplete data were presented in a particular report, the corresponding authors were contacted about provision of data in a usable format. The metaanalysis was performed employing the Mantel-Haenszel approach as a fixed-effects model test and the DerSimonian-Laird method as a random-effects model test, using StatsDirect statistical software (version 2.6.2; StatsDirect Ltd, Sale, UK). We selected a nominal $P$ value of 0.05 as significant to maximize confidence in a true-positive association and to minimize false-positive results. The Cochran $Q$ test for heterogeneity was used to assess whether variability among studies was greater than expected by chance alone. When the ORs are homogeneous, the $Q$ follows a $\chi^{2}$ distribution with $r-1(r$ is the number of studies) degrees of freedom $(d f)$. If $P<0.10$, then heterogeneity was considered statistically significant. In addition, the $I^{2}$ metric $\left[I^{2}=(\mathrm{Q}-d f) / Q\right]$ was used to describe the percentage of variation across studies due to heterogeneity rather than chance. The $I^{2}$ takes values between 0 and $100 \%$ with higher values denoting a greater degree of heterogeneity $\left(I^{2}=0-25 \%\right.$, absence; $25-50 \%$, moderate; $50-75 \%$, large; 75-100\%, extreme heterogeneity). Publication bias was not assessed because of the small number of studies available.

\section{Results}

A replication case-control study of the selected RAcandidate SNPs

For the present study, we chose one SNP from each of four highly plausible RA-susceptibility genes: rs2240340/ padi4_94 for PADI4, rs7528684/fcrl3_3 for FCRL3, rs3792876/slc2F2 for SLC22A4, and rs2268277/runxl for RUNX1 (see ESM Table 2 for general information on the selected SNPs). These SNPs display either the highest association signals in the original studies or a near complete pairwise LD with the most significantly associated SNPs. In addition, potential functional effects for at least three SNPs were described previously. Initially, in an attempt to replicate the reported effects of the selected SNPs, we genotyped a case-control sample set consisting of 950 unrelated Japanese RA patients and 507 controls. Our case and control subjects had not previously been tested for the selected SNPs, and were thus completely independent of those previously reported by other investigators. The statistical power of our study to detect genotype differences of the magnitude reported in the initial positive studies was more than $90 \%$ (type I error rate $0.05)$.

Genotype and allele frequencies of the selected SNPs in our study population are shown in Table 1 . None of the SNPs showed any deviations from HWE in either the case or the control group. Only the allele and genotype frequencies of rs2240340/padi4_94 showed weak but significant $(P<0.05)$ associations with RA. The minor allele frequency of rs2240340/padi4_94 was 0.447 in cases and 0.399 in controls, yielding an allelic OR of $1.22(95 \%$ CI 1.04-2.12, $P=0.012)$. Armitage's trend test yielded similar values (OR 1.23, $P=0.011)$. The highest significant OR was found for the genotype contrast of homozygotes (genotype 11 vs. 22; OR 1.53, 95\% CI 1.102.12, $P=0.010$ ). Logistic regression analysis revealed that associations between rs2240340/padi4_94 and RA remained statistically significant after adjustment for age and sex (data not shown). In the remaining SNPs (rs7528684/fcrl3_3, rs3792876/slc2F2 and rs2268277/ runx 1), no significant difference in either allele or genotype frequencies was observed in our case-control sample set.

Meta-analysis of East Asian population studies

We summarized the data from the current study, compared them with those from previous association studies and carried out meta-analyses (the descriptive characteristics and results of each of the prior studies are tabulated in ESM Table 3). We considered only the East Asian populations for the meta-analysis and included four previously published case-control association studies of RA on PADI4, three each on FCRL3 and SLC22A4, and two on RUNX1 genes. All except for the three Korean reports were Japanese population studies. The ORs, which were recalculated for each individual study, are shown in ESM Table 4. In each one of the PADI4 and SLC22A4 reports, genotype data on the selected SNPs were unavailable because they used different SNPs for the association analyses. For the meta-analysis of PADI4, we decided to pool genotype data for the two SNPs, rs2240340/padi4_94 and rs874881/ padi4_92, because the latter (a nonsynonymous PADI4 [G112A] SNP) is separated by only $2.14 \mathrm{~kb}$ from the former, and the two SNPs were found to be in complete LD among our 507 unrelated Japanese control subjects (pairwise $r^{2}=1$; Y.T., unpublished data). For a similar reason, we pooled data for the two SLC22A4 SNPs, rs2073838/ slc $2 F 1$ and $\mathrm{rs} 3792876 /$ slc $2 F 2$, previously reported to be in almost complete LD ( $\Delta$ or $r^{2}>0.97$ ) (Tokuhiro et al. 


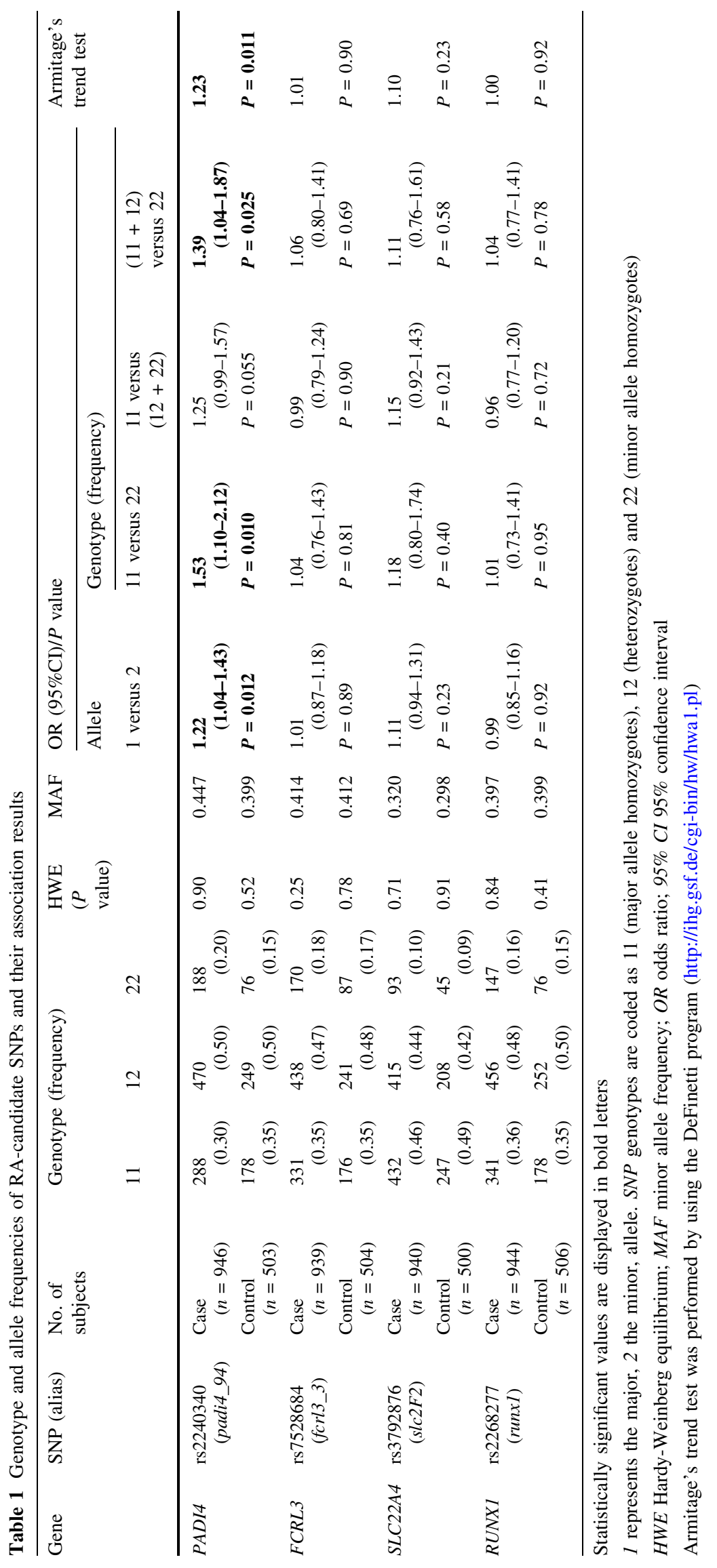


2003). In addition, since there was an overlap of case subjects in the two Korean studies of PADI4 SNPs (Kang et al. 2006; Cha et al. 2007), we excluded duplicate/overlapping data for the meta-analysis (data provided courtesy of Dr. C. Kang). The meta-analysis results are presented in Table 2, and the forest plots, illustrating the study-specific and summary ORs with 95\% CIs, are shown in Fig. 1 (allelic association) and ESM Fig. 1a-c (genotypic contrasts).

\section{PADI4}

In total, the PADI4 SNPs studies for the meta-analysis included 3,713 RA cases and 2,485 controls (Table 2). The summary OR calculated for allele distributions was 1.31 (95\% CI 1.22-1.41, $P<0.0001$ ) under a fixed-effects model, and 1.32 (95\% CI 1.20-1.45, $P<0.0001)$ under a random-effects model (Fig. 1a). There was no obvious inter-study OR heterogeneity $(Q$ test $P=0.22$, $\left.I^{2}=31.5 \%\right)$. The genotype contrast of the homozygotes (11 vs. 22) produced a maximum OR (fixed-effects OR $1.72,95 \%$ CI 1.48-2.01, $P<0.0001$; random-effects OR $1.73,95 \%$ CI $1.46-2.05, P<0.0001)$, while the dominant [11 vs. $(12+22)]$ and recessive $[(11+12)$ vs. 22$]$ models also showed significant effects. With the exclusion of data from the initial positive study, thus restricting the analysis to replication series only (2,891 cases and 1,839 controls), the summary ORs decreased slightly, but remained highly significant.

\section{FCRL3}

Across all five studies, the minor allele of the rs7528684/ fcrl3_3 was positively associated with RA, with a randomeffects summary OR of 1.16 (95\% CI 1.06-1.28, $P=0.0022 ; 4,111$ cases and 3,420 controls; Table 2, Fig. 1b), although a moderate to large inter-study heterogeneity was noted ( $Q$ test $P=0.075, I^{2}=52.9 \%$ ). After exclusion of the initial samples used by Kochi et al. (2005), in which a deviation from HWE at the 5\% significance level was detected in controls $(P=0.037$; ESM Table 4$)$, the heterogeneity disappeared ( $Q$ test $\left.P=0.44, I^{2}=0 \%\right)$, and the ORs were still significant (fixed-effects OR 1.12, 95\% CI 1.04-1.20, $P=0.0034$; random-effects OR $1.12,95 \%$ CI $1.04-1.20, P=0.0032)$. The genotype contrast of the homozygotes (11 vs. 22 ) produced the maximum OR under both fixed- and random-effects models (ORs 1.24-1.40); however, the magnitude of associations was considerably smaller than the effect estimated in the initial positive study (i.e., homozygosity OR 2.24) (Kochi et al. 2005).

\section{$S L C 22 A 4$}

Based on the allele distributions, no heterogeneity was observed $\left(Q\right.$ test $P=0.37, I^{2}=0 \% ; 2,626$ cases and 2,096 controls), and the summary ORs were significant (fixed-effects OR 1.14, 95\% CI 1.04-1.24, $P=0.0036$; random-effects OR 1.14, 95\% CI 1.04-1.24, $P=0.0034$; Table 2, Fig. 1c). However, there were substantial levels of inter-study heterogeneities in either the genotype contrast of the homozygotes or the recessive model ( $Q$ test $P=0.10$ and $0.040, I^{2}=55.9$ and $68.9 \%$, respectively). This appeared to be driven primarily by the excess of minor allele homozygotes among cases in the original study by Tokuhiro et al. (2003), which also showed a significant departure from HWE $(P=0.000037$; ESM Table 4 ), since this heterogeneity disappeared when the study was excluded. When restricted to replication series only (1,807 cases and 1,440 controls), the summary ORs under both fixed- and random-effects models were not significant for any of the allele/genotype contrasts examined.

\section{RUNX1}

Meta-analysis of the allele and genotype contrasts of rs2268277/runxl revealed extreme heterogeneity between studies ( $Q$ test $P<0.01, I^{2}>75 \%$; Table 2). In a randomeffects model, the summary OR was not significant $(P>0.05)$. When the first positive study $(1,813$ cases and 1,453 controls) was excluded, the heterogeneity disappeared ( $Q$ test $P>0.1$ ), while the summary ORs remained non-significant, with the trend actually being in the opposite direction (Fig. 1d).

\section{Discussion}

In the current study, we performed population-based association tests for the PADI4, FCRL3, SLC22A4 and RUNX1 genes, all of which had prior strong evidence of associations with RA. We selected one SNP from each gene (rs2240340/padi4_94, rs7528684/fcrl3_3, rs3792876/ slc2F2 and rs2268277/runxl) and tested in an independent replication panel, consisting of a total of 1,457 Japanese subjects (950 RA cases and 507 controls). Our results demonstrated that only SNP rs2240340/padi4_94 in the PADI4 gene showed significant, reproducible allelic and genotypic associations, whereas no statistically significant differences between cases and controls were observed for the remaining SNPs in either allele or genotype frequencies. 
Table 2 Meta-analysis of RA-candidate SNPs and their genetic associations with RA

\begin{tabular}{|c|c|c|c|c|c|c|c|c|c|c|}
\hline \multirow[t]{2}{*}{ Gene } & \multirow[t]{2}{*}{ Studies (no.) } & \multirow{2}{*}{$\begin{array}{l}\text { Genetic } \\
\text { constrasts }\end{array}$} & \multirow{2}{*}{$\begin{array}{l}\text { No. of } \\
\text { subjects } \\
\text { (case/ } \\
\text { control) }\end{array}$} & \multicolumn{2}{|l|}{ Cochran $Q$} & \multirow[t]{2}{*}{$I^{2}(95 \% \mathrm{CI})$} & \multicolumn{2}{|l|}{ Fixed effects } & \multicolumn{2}{|l|}{ Random effects } \\
\hline & & & & $Q(d f)$ & $\begin{array}{l}P \\
\text { value }\end{array}$ & & OR $(95 \%$ CI $)$ & $P$ value & OR $(95 \%$ CI $)$ & $P$ value \\
\hline \multirow[t]{8}{*}{ PADI4 } & \multirow[t]{4}{*}{ All (4) } & 1 versus 2 & $\begin{array}{r}3,713 / \\
2,485\end{array}$ & $4.38(3)$ & 0.22 & $\begin{array}{l}31.5 \%(0- \\
77.0)\end{array}$ & $\begin{array}{l}1.31(1.22- \\
1.41)\end{array}$ & $<\mathbf{0 . 0 0 0 1}$ & $\begin{array}{l}1.32(1.20- \\
1.44)\end{array}$ & $<\mathbf{0 . 0 0 0 1}$ \\
\hline & & 11 versus 22 & $\begin{array}{r}1,853 / \\
1,296\end{array}$ & $3.59(3)$ & 0.31 & $\begin{array}{c}16.5 \%(0- \\
72.9)\end{array}$ & $\begin{array}{l}1.72(1.48- \\
2.01)\end{array}$ & $<\mathbf{0 . 0 0 0 1}$ & $\begin{array}{l}1.73(1.46- \\
2.05)\end{array}$ & $<\mathbf{0 . 0 0 0 1}$ \\
\hline & & $\begin{array}{l}11 \text { versus } \\
\quad(12+22)\end{array}$ & $\begin{array}{l}3,713 / \\
2,485\end{array}$ & $4.40(3)$ & 0.22 & $\begin{array}{l}31.9 \%(0- \\
77.1)\end{array}$ & $\begin{array}{l}1.42(1.27- \\
1.58)\end{array}$ & $<\mathbf{0 . 0 0 0 1}$ & $\begin{array}{l}1.42(1.25- \\
1.63)\end{array}$ & $<\mathbf{0 . 0 0 0 1}$ \\
\hline & & $\begin{array}{l}(11+12) \\
\text { versus } 22\end{array}$ & $\begin{array}{l}3,713 / \\
2,485\end{array}$ & $1.63(3)$ & 0.65 & $0 \%(0-67.9)$ & $\begin{array}{l}1.46(1.27- \\
1.67)\end{array}$ & $<\mathbf{0 . 0 0 0 1}$ & $\begin{array}{l}1.46(1.27- \\
1.67)\end{array}$ & $<0.0001$ \\
\hline & \multirow[t]{4}{*}{$\begin{array}{l}\text { Replication } \\
\text { (3) }\end{array}$} & 1 versus 2 & $\begin{array}{l}2,891 / \\
1,839\end{array}$ & 3.33 (2) & 0.19 & $\begin{array}{l}39.9 \%(0- \\
82.3)\end{array}$ & $\begin{array}{l}1.28(1.18- \\
1.40)\end{array}$ & $<0.0001$ & $\begin{array}{l}1.29(1.16- \\
1.44)\end{array}$ & $<\mathbf{0 . 0 0 0 1}$ \\
\hline & & 11 versus 22 & $1,446 / 955$ & $2.65(2)$ & 0.27 & $\begin{array}{c}24.4 \%(0- \\
78.9)\end{array}$ & $\begin{array}{l}1.65(1.39- \\
1.97)\end{array}$ & $<\mathbf{0 . 0 0 0 1}$ & $\begin{array}{l}1.66(1.36- \\
2.04)\end{array}$ & $<\mathbf{0 . 0 0 0 1}$ \\
\hline & & $\begin{array}{l}11 \text { versus } \\
(12+22)\end{array}$ & $\begin{array}{l}2,891 / \\
1,839\end{array}$ & $3.51(2)$ & 0.17 & $\begin{array}{l}43.1 \%(0- \\
83.0)\end{array}$ & $\begin{array}{l}1.37(1.21- \\
1.56)\end{array}$ & $<\mathbf{0 . 0 0 0 1}$ & $\begin{array}{l}1.39(1.17- \\
1.64)\end{array}$ & 0.0001 \\
\hline & & $\begin{array}{l}(11+12) \\
\text { versus } 22\end{array}$ & $\begin{array}{r}2,891 / \\
1,839\end{array}$ & $1.11(2)$ & 0.58 & $0 \%(0-72.9)$ & $\begin{array}{l}1.42(1.21- \\
1.66)\end{array}$ & $<\mathbf{0 . 0 0 0 1}$ & $\begin{array}{l}1.42(1.21- \\
1.66)\end{array}$ & $<\mathbf{0 . 0 0 0 1}$ \\
\hline \multirow[t]{8}{*}{$F C R L 3$} & \multirow[t]{4}{*}{ All (5) } & 1 versus 2 & $\begin{array}{l}4,111 / \\
3,420\end{array}$ & $8.48(4)$ & 0.075 & $\begin{array}{l}52.9 \%(0- \\
80.7)\end{array}$ & $\begin{array}{l}1.16(1.09- \\
1.24)\end{array}$ & $<\mathbf{0 . 0 0 0 1}$ & $\begin{array}{l}1.16(1.06- \\
1.28)\end{array}$ & 0.0022 \\
\hline & & 11 versus 22 & $\begin{array}{r}2,120 / \\
1,762\end{array}$ & $12.7(4)$ & 0.013 & $\begin{array}{l}68.5 \%(0- \\
85.7)\end{array}$ & $\begin{array}{l}1.39(1.21- \\
1.59)\end{array}$ & $<0.0001$ & $\begin{array}{l}1.40(1.09- \\
1.80)\end{array}$ & 0.0088 \\
\hline & & $\begin{array}{l}11 \text { versus } \\
\quad(12+22)\end{array}$ & $\begin{array}{l}4,111 / \\
3,420\end{array}$ & $3.41(4)$ & 0.49 & $0 \%(0-64.1)$ & $\begin{array}{l}1.18(1.08- \\
1.30)\end{array}$ & 0.0007 & $\begin{array}{l}1.18(1.07- \\
1.30)\end{array}$ & 0.0006 \\
\hline & & $\begin{array}{l}(11+12) \\
\quad \text { versus } 22\end{array}$ & $\begin{array}{l}4,111 / \\
\quad 3,420\end{array}$ & $15.4(4)$ & 0.0039 & $\begin{array}{l}74.0 \%(0.3- \\
87.6)\end{array}$ & $\begin{array}{l}1.29(1.14- \\
1.47)\end{array}$ & $<0.0001$ & $\begin{array}{l}1.31(1.02- \\
1.68)\end{array}$ & 0.036 \\
\hline & \multirow[t]{4}{*}{$\begin{array}{l}\text { Replication } \\
\text { (4) }\end{array}$} & 1 versus 2 & $\begin{array}{l}3,287 / \\
2,771\end{array}$ & $2.70(3)$ & 0.44 & $0 \%(0-67.9)$ & $\begin{array}{l}1.12(1.04- \\
1.20)\end{array}$ & 0.0034 & $\begin{array}{l}1.12(1.04- \\
1.20)\end{array}$ & 0.0032 \\
\hline & & 11 versus 22 & $\begin{array}{l}1,670 / \\
1,431\end{array}$ & $2.90(3)$ & 0.41 & $0 \%(0-67.9)$ & $\begin{array}{l}1.24(1.07- \\
1.45)\end{array}$ & 0.0063 & $\begin{array}{l}1.24(1.07- \\
1.45)\end{array}$ & 0.0056 \\
\hline & & $\begin{array}{l}11 \text { versus } \\
\quad(12+22)\end{array}$ & $\begin{array}{l}3,287 / \\
2,771\end{array}$ & $2.85(3)$ & 0.42 & $0 \%(0-67.9)$ & $\begin{array}{l}1.16(1.04- \\
1.29)\end{array}$ & 0.0071 & $\begin{array}{l}1.16(1.04- \\
1.29)\end{array}$ & 0.0066 \\
\hline & & $\begin{array}{l}(11+12) \text { versus } \\
22\end{array}$ & $\begin{array}{l}3,287 / \\
2,771\end{array}$ & $2.58(3)$ & 0.46 & $0 \%(0-67.9)$ & $\begin{array}{l}1.16(1.01- \\
1.33)\end{array}$ & 0.045 & $\begin{array}{l}1.16(1.01- \\
1.33)\end{array}$ & 0.041 \\
\hline \multirow[t]{8}{*}{$S L C 22 A 4$} & \multirow[t]{4}{*}{ All (3) } & 1 versus 2 & $\begin{array}{l}2,626 / \\
2,096\end{array}$ & $2.00(2)$ & 0.37 & $0 \%(0-72.9)$ & $\begin{array}{l}1.14(1.04- \\
1.24)\end{array}$ & 0.0036 & $\begin{array}{c}1.14(1.04- \\
1.24)\end{array}$ & 0.0034 \\
\hline & & 11 versus 22 & $\begin{array}{l}1,507 / \\
1,178\end{array}$ & $4.53(2)$ & 0.10 & $\begin{array}{l}55.9 \%(0- \\
85.8)\end{array}$ & $\begin{array}{l}1.43(1.17- \\
1.74)\end{array}$ & 0.0005 & $\begin{array}{l}1.42(1.05- \\
1.92)\end{array}$ & 0.022 \\
\hline & & $\begin{array}{l}11 \text { versus } \\
\quad(12+22)\end{array}$ & $\begin{array}{l}2,626 / \\
2,096\end{array}$ & $0.33(2)$ & 0.85 & $0 \%(0-72.9)$ & $\begin{array}{l}1.10(0.98- \\
1.24)\end{array}$ & 0.12 & $\begin{array}{l}1.10(0.98- \\
1.24)\end{array}$ & 0.11 \\
\hline & & $\begin{array}{l}(11+12) \\
\quad \text { versus } 22\end{array}$ & $\begin{array}{l}2,626 / \\
2,096\end{array}$ & $6.42(2)$ & 0.040 & $\begin{array}{l}\text { 68.9\% }(0- \\
88.8)\end{array}$ & $\begin{array}{l}1.42(1.18- \\
1.71)\end{array}$ & 0.0003 & $\begin{array}{l}1.40(1.00- \\
1.98)\end{array}$ & 0.053 \\
\hline & \multirow[t]{4}{*}{$\begin{array}{l}\text { Replication } \\
\text { (2) }\end{array}$} & 1 versus 2 & $\begin{array}{l}1,807 / \\
1,440\end{array}$ & $0.04(1)$ & 0.84 & - & $\begin{array}{l}1.09(0.98- \\
1.21)\end{array}$ & 0.11 & $\begin{array}{l}1.09(0.98- \\
1.21)\end{array}$ & 0.11 \\
\hline & & 11 versus 22 & $1,009 / 810$ & $0.050(1)$ & 0.82 & - & $\begin{array}{l}1.22(0.96- \\
1.56)\end{array}$ & 0.12 & $\begin{array}{l}1.22(0.96- \\
1.56)\end{array}$ & 0.10 \\
\hline & & $\begin{array}{l}11 \text { versus } \\
\quad(12+22)\end{array}$ & $\begin{array}{l}1,807 / \\
1,440\end{array}$ & $0.32(1)$ & 0.57 & - & $\begin{array}{l}1.09(0.95- \\
1.26)\end{array}$ & 0.22 & $\begin{array}{l}1.09(0.95- \\
1.26)\end{array}$ & 0.21 \\
\hline & & $\begin{array}{l}(11+12) \\
\text { versus } 22\end{array}$ & $\begin{array}{l}1,807 / \\
1,440\end{array}$ & $0.21(1)$ & 0.65 & - & $\begin{array}{c}1.19(0.94- \\
1.50)\end{array}$ & 0.16 & $\begin{array}{c}1.19(0.94- \\
1.50)\end{array}$ & 0.14 \\
\hline
\end{tabular}


Table 2 continued

\begin{tabular}{|c|c|c|c|c|c|c|c|c|c|c|}
\hline \multirow[t]{2}{*}{ Gene } & \multirow[t]{2}{*}{ Studies (no.) } & \multirow{2}{*}{$\begin{array}{l}\text { Genetic } \\
\text { constrasts }\end{array}$} & \multirow{2}{*}{$\begin{array}{l}\text { No. of } \\
\text { subjects } \\
\text { (case/ } \\
\text { control) }\end{array}$} & \multicolumn{2}{|c|}{ Cochran $Q$} & \multirow[t]{2}{*}{$I^{2}(95 \% \mathrm{CI})$} & \multicolumn{2}{|l|}{ Fixed effects } & \multicolumn{2}{|c|}{ Random effects } \\
\hline & & & & $Q(d f)$ & $\begin{array}{l}P \\
\text { value }\end{array}$ & & OR $(95 \% \mathrm{CI})$ & $\begin{array}{l}P \\
\text { value }\end{array}$ & OR $(95 \% \mathrm{CI})$ & $\begin{array}{l}P \\
\text { value }\end{array}$ \\
\hline \multirow[t]{8}{*}{$R U N X 1$} & \multirow[t]{4}{*}{ All (3) } & 1 versus 2 & $2,633 / 2,103$ & $11.5(2)$ & 0.0032 & $\begin{array}{l}82.6 \%(0- \\
92.5)\end{array}$ & $\begin{array}{c}1.04(0.96- \\
1.13)\end{array}$ & 0.39 & $\begin{array}{c}1.05(0.86- \\
1.28)\end{array}$ & 0.65 \\
\hline & & 11 versus 22 & $1,318 / 1,091$ & $9.29(2)$ & 0.0096 & $\begin{array}{l}78.5 \%(0- \\
91.3)\end{array}$ & $\begin{array}{c}1.05(0.88- \\
1.25)\end{array}$ & 0.60 & $\begin{array}{c}1.07(0.73- \\
1.57)\end{array}$ & 0.73 \\
\hline & & $\begin{array}{l}11 \text { versus } \\
(12+22)\end{array}$ & $2,633 / 2,103$ & $11.6(2)$ & 0.0030 & $\begin{array}{l}82.8 \%(0- \\
92.6)\end{array}$ & $\begin{array}{c}1.09(0.96- \\
1.23)\end{array}$ & 0.19 & $\begin{array}{c}1.09(0.82- \\
1.47)\end{array}$ & 0.55 \\
\hline & & $\begin{array}{l}(11+12) \\
\quad \text { versus } 22\end{array}$ & $2,633 / 2,103$ & $4.70(2)$ & 0.095 & $\begin{array}{l}57.4 \%(0- \\
86.2)\end{array}$ & $\begin{array}{c}1.00(0.85- \\
1.17)\end{array}$ & 0.98 & $\begin{array}{c}1.01(0.79- \\
1.29)\end{array}$ & 0.95 \\
\hline & \multirow[t]{4}{*}{$\begin{array}{l}\text { Replication } \\
\text { (2) }\end{array}$} & 1 versus 2 & $1,813 / 1,453$ & $0.66(1)$ & 0.42 & - & $\begin{array}{l}0.94(0.85- \\
1.04)\end{array}$ & 0.28 & $\begin{array}{l}0.94(0.85- \\
1.04)\end{array}$ & 0.27 \\
\hline & & 11 versus 22 & $921 / 736$ & $1.09(1)$ & 0.30 & - & $\begin{array}{c}0.88(0.71- \\
1.09)\end{array}$ & 0.27 & $\begin{array}{c}0.88(0.71- \\
1.10)\end{array}$ & 0.28 \\
\hline & & $\begin{array}{l}11 \text { versus } \\
(12+22)\end{array}$ & $1,813 / 1,453$ & $0.05(1)$ & 0.82 & - & $\begin{array}{c}0.94(0.81- \\
1.09)\end{array}$ & 0.44 & $\begin{array}{c}0.94(0.81- \\
1.09)\end{array}$ & 0.41 \\
\hline & & $\begin{array}{l}(11+12) \\
\quad \text { versus } 22\end{array}$ & $1,813 / 1,453$ & $1.52(1)$ & 0.22 & - & $\begin{array}{c}0.90(0.75- \\
1.09)\end{array}$ & 0.32 & $\begin{array}{c}0.91(0.72- \\
1.16)\end{array}$ & 0.44 \\
\hline
\end{tabular}

Statistically significant values are displayed in bold letters

1 represents the major, 2 the minor, allele. SNP genotypes are coded as 11 (major allele homozygotes), 12 (heterozygotes) and 22 (minor allele homozygotes)

OR odds ratio; $95 \%$ CI 95\% confidence interval; $d f$ degree of freedom

In our sample set, the association of rs2240340/ padi4_94 was only modest (allelic OR 1.22, $P=0.012$; Table 1). The most significant association with RA susceptibility was observed in the contrast of homozygotes (genotype 11 vs 22; OR 1.53, $P=0.010$ ), a consistent observation already suggested in the original report by Suzuki et al. (2003). To our knowledge, our study is the third follow-up replication cohort examining the relationship between the PADI4 polymorphisms and RA in East Asians. In all studies, the association was ultimately found to be consistently significant (see Fig. 1a), reinforcing the notion that PADI4 gene polymorphisms contribute to the development of RA in this ethnic group. When published genotype data of the two tightly linked SNPs, rs2240340/ padi4_94 and rs874881/padi4_92, were combined, the updated allelic summary OR was 1.31 (fixed-effects), a value similar to those from previous meta-analyses in East Asians (Iwamoto et al. 2006; Lee et al. 2007). Although this study focused on East Asian populations, it is important to ascertain whether PADI4 SNPs confer RA risk in a race-specific manner. In white populations, previous association studies have produced inconsistent results (Barton et al. 2005a; Harney et al. 2005; Martinez et al. 2005; Plenge et al. 2005; Hoppe et al. 2006). However, recent ethnicity-specific meta-analyses have suggested that the padi4_94 SNP may be associated with increased risk of RA in Europeans, although the magnitude of association seemed to be much smaller than that in Asians, and further analysis with a much larger sample size is therefore needed to draw a conclusion (Iwamoto et al. 2006; Lee et al. 2007).

Unfortunately, the exact nature of causal variant(s) within the PADI4 gene responsible for RA susceptibility is currently unknown. Suzuki et al. (2003) identified at least three missense variants of PADI4, including G55S, V82A and G112A (rs874881/padi4_92), which are tightly linked with each other, and any of these may have functional significance. In addition, it has been reported that the susceptibility haplotype, which is marked by diseaseassociated SNPs including rs2240340/padi4_94 and rs874881/padi4_92, affects the stability of PADI4 transcripts, raising the possibility that variants in intronic or non-coding regions may alter transcriptional regulation, thus contributing to the pathogenic consequences. Further studies, including extensive genetic analyses in diverse ethnic groups with different LD characteristics, as well as biochemical evaluations, are warranted to identify actual causal variant(s) and to better understand the role of PADI4 in the development of RA.

Although we failed to detect significant associations for the FCRL3, SLC22A4 and RUNX1 SNPs in our replication sample set, the meta-analyses of East Asian studies showed evidence of FCRL3 and SLC22A4 associations $(P=0.0022$ and 0.0034 , respectively; see Table 2, Fig. 1b, c). However, these results should be interpreted 

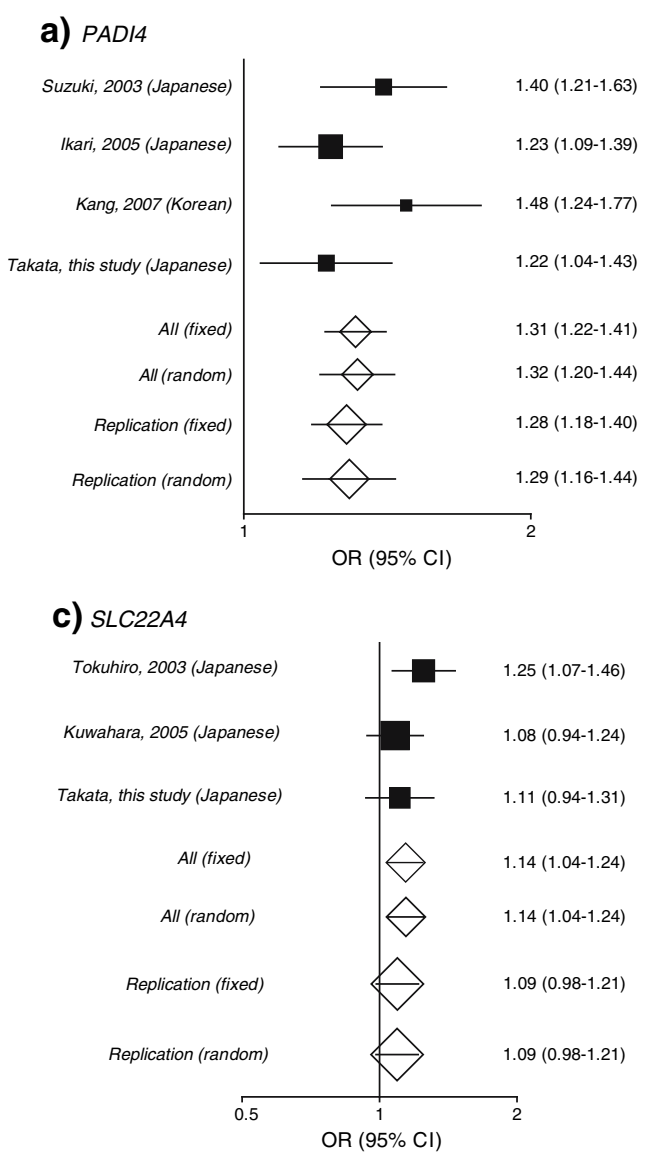

Fig. 1 Meta-analysis of the allelic association between selected candidate genes and RA in East Asian populations. A meta-analysis plot for the allelic associations (allele 1 vs. 2) is shown here. Black squares indicate the study-specific odds ratios (ORs), with the size of each square being inversely proportional to its variance, and horizontal lines represent the $95 \%$ confidence intervals (CIs). The

with much greater caution for several reasons. First, although individual studies included in the meta-analysis were relatively large with reasonable statistical powers and further power improvement can be expected by metaanalysis, power still appears to be inadequate to detect such a small genetic effect (i.e., OR $<1.2$ ). Unfortunately, power calculations for meta-analysis are controversial and therefore were not conducted in this study. However, when statistical power is estimated simply using the summary ORs and their allele frequencies, over 6,000 (for FCRL3) and 8,000 (for SLC22A4) subjects (assuming equal number of cases and controls) will be required to achieve $80 \%$ power to detect a true allelic association at the 5\% significance level. Thus, many more subjects are apparently required for the assessment of SLC22A4 SNPs. Second, for each meta-analysis, there was a considerable level of inter-study OR heterogeneity. The removal of initial positive reports (thus restricting this analysis to
Allele

\section{b) FCRL3}

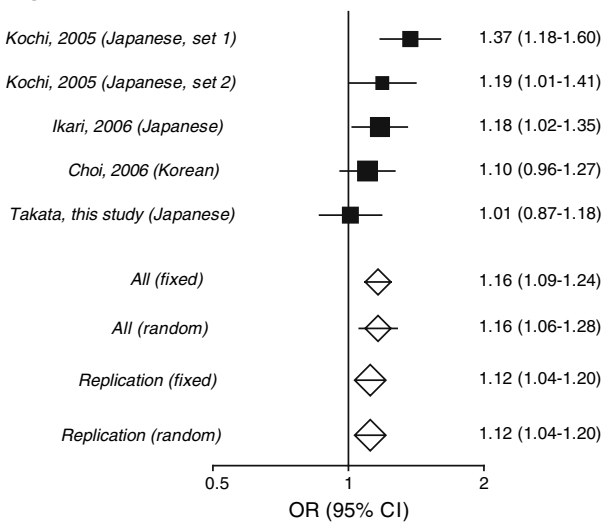

\section{d) RUNX1}

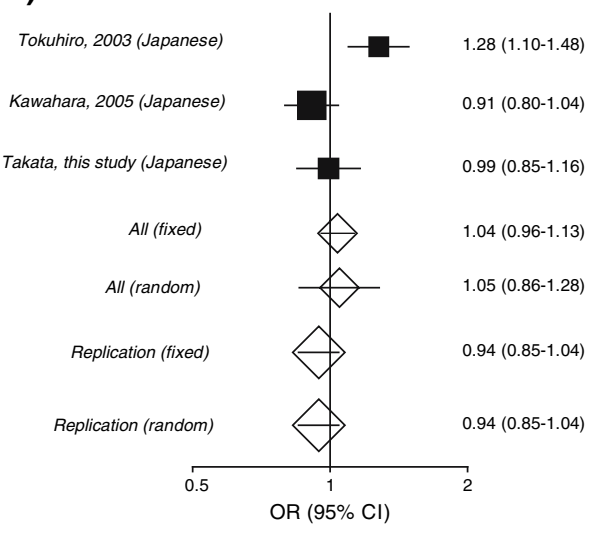

summary ORs and their 95\% CI were calculated separately for the "All" and "Replication" studies, using fixed- and random-effects approaches, and are indicated by the unshaded diamonds. a PADI4 (rs2240340/padi4_94 or rs874881/padi4_92); b FCRL3 (rs7528684/ fcrl3_3); c SLC22A4 (rs3792876/slc2F2 or rs2073838/slc2F1); and d RUNX1 gene (rs2268277/runxl)

replication studies) greatly diminished the heterogeneities, and the FCRL3 SNP remained significant, whereas $S L C 22 A 4$ SNPs became non-significant. These procedures, however, could further reduce the available statistical power and limit the capacity to detect small effects, and may produce false-negative results. Third, the magnitudes of individual effects were likely to be much weaker than those reported in the first positive reports. In addition, the updated allele fixed-effects summary OR for rs7528684/ fcrl3_3 was 1.16 , showing a trend toward a decrease as compared with an OR of 1.20 for East Asian subjects, provided by a previously published meta-analysis (Begovich et al. 2007). These are perhaps because the risk effects may have been overestimated in the first reports, consistent with a phenomenon known as the "winner's curse" effect (Lohmueller et al. 2003). Lastly, several other methodological limitations of a meta-analysis should also be considered. A publication and reporting bias could 
be present, because it has not been long since the first reports of gene association and, to date, only a few publications are available. On the other hand, adverse effects due to the differences in LD pattern across populations will be less problematic, because (1) the present study population was eventually restricted to Japanese and Korean populations, which are geographically and historically closely related and genetically quite similar to each other (Kim et al. 2005), and (2) most of the selected SNPs were themselves proposed to be putative causal variants. It should also be mentioned that, due to limited information, this meta-analysis was based on unadjusted estimates, and a more precise analysis could be performed with adjustment for potential confounding factors (e.g., gender, age, disease duration, SE allele and autoantibody status). Other possibilities include technical artifacts (e.g., genotyping error), unrecognized bias (due to differences in the ascertainment of either case or control populations, clinical severity and genetic/familial loading of case subjects, or an unmeasured variable), hidden population stratification or gene-environment interactions. Overall, we believe that more independent studies, with even larger sample sizes and subsequent updates of the meta-analysis results will be required to determine the precise impacts of these genes in RA susceptibility in East Asians.

In summary, our results and meta-analysis do support the hypothesis that $P A D I 4$ polymorphisms contribute substantially to the development of RA in East Asian populations. Our case-control study failed to replicate the reported associations for the FCRL3, SLC22A4 and RUNX1 SNPs. We emphasize herein the importance of reporting non-significant results to avoid distorting the body of publicly available data. While meta-analysis indicated some evidence of association between the FCRL3 and SLC22A4 SNPs and RA, their impact on RA in East Asians seems much more limited than previously thought. Nevertheless, even a small genetic risk may identify a gene with an important biological role that could yield new mechanistic insights and provide novel therapeutic targets. Finally, our results add to our understanding of the genetic basis of RA and emphasize the need for additional association studies with greater statistical power and updated meta-analysis.

Acknowledgments We would like to thank our patients and volunteer blood donors for participating in this study. We thank Dr. Katsunori Ikari (Tokyo Women's Medical University, Tokyo, Japan), Professor Changwon Kang (Korea Advanced Institute of Science and Technology, Daejeon, Korea) and Professor Sang-Cheol Bae (Hanyang University, Seoul, Korea) for their generosity in providing additional information regarding the genotype information described in their reports. We also thank the many past and present members of our research group for helpful discussions. This study was partially funded by grants from the Ministry of Education, Science and Technology (Knowledge Cluster Initiative).

\section{References}

Arnett FC, Edworthy SM, Bloch DA, McShane DJ, Fries JF, Cooper NS, Healey LA, Kaplan SR, Liang MH, Luthra HS, Medsger TAJ, Mitchell DM, Neustadt DH, Pinals RS, Schaller JG, Sharp JT, Wilder RL, Hunder GG (1988) The American Rheumatism Association 1987 revised criteria for the classification of rheumatoid arthritis. Arthritis Rheum 31:315-324

Barton A, Bowes J, Eyre S, Symmons D, Worthington J, Silman A (2005a) Investigation of polymorphisms in the PADI4 gene in determining severity of inflammatory polyarthritis. Ann Rheum Dis 64:1311-1315

Barton A, Eyre S, Bowes J, Ho P, John S, Worthington J (2005b) Investigation of the SLC22A4 gene (associated with rheumatoid arthritis in a Japanese population) in a United Kingdom population of rheumatoid arthritis patients. Arthritis Rheum 52:752-758

Begovich AB, Carlton VE, Honigberg LA, Schrodi SJ, Chokkalingam AP, Alexander HC, Ardlie KG, Huang Q, Smith AM, Spoerke JM, Conn MT, Chang M, Chang SY, Saiki RK, Catanese JJ, Leong DU, Garcia VE, McAllister LB, Jeffery DA, Lee AT, Batliwalla F, Remmers E, Criswell LA, Seldin MF, Kastner DL, Amos CI, Sninsky JJ, Gregersen PK (2004) A missense singlenucleotide polymorphism in a gene encoding a protein tyrosine phosphatase (PTPN22) is associated with rheumatoid arthritis. Am J Hum Genet 75:330-337

Begovich AB, Chang M, Schrodi SJ (2007) Meta-analysis evidence of a differential risk of the FCRL3 $-169 \mathrm{~T} \rightarrow \mathrm{C}$ polymorphism in white and East Asian rheumatoid arthritis patients. Arthritis Rheum 56:3168-3171

Cha S, Choi CB, Han TU, Kang CP, Kang C, Bae SC (2007) Association of anti-cyclic citrullinated peptide antibody levels with PADI4 haplotypes in early rheumatoid arthritis and with shared epitope alleles in very late rheumatoid arthritis. Arthritis Rheum 56:1454-1463

Choi CB, Kang CP, Seong SS, Bae SC, Kang C (2006) The -169C/T polymorphism in FCRL3 is not associated with susceptibility to rheumatoid arthritis or systemic lupus erythematosus in a casecontrol study of Koreans. Arthritis Rheum 54:3838-3841

de Vries RR, Huizinga TW, Toes RE (2005) Redefining the HLA and RA association: to be or not to be anti-CCP positive. J Autoimmun 25(Suppl):21-25

Eyre S, Bowes J, Potter C, Worthington J, Barton A (2006) Association of the FCRL3 gene with rheumatoid arthritis: a further example of population specificity? Arthritis Res Ther 8:R117

Fisher SA, Hampe J, Onnie CM, Daly MJ, Curley C, Purcell S, Sanderson J, Mansfield J, Annese V, Forbes A, Lewis CM, Schreiber S, Rioux JD, Mathew CG (2006) Direct or indirect association in a complex disease: the role of SLC22A4 and $S L C 22 A 5$ functional variants in Crohn disease. Hum Mutat 27:778-785

Gregersen PK, Lee HS, Batliwalla F, Begovich AB (2006) PTPN22: setting thresholds for autoimmunity. Semin Immunol 18:214223

Hamada D, Takata Y, Osabe D, Nomura K, Shinohara S, Egawa H, Nakano S, Shinomiya F, Scafe CR, Reeve VM, Miyamoto T, Moritani M, Kunika K, Inoue H, Yasui N, Itakura M (2005) Association between single-nucleotide polymorphisms in the SEC8L1 gene, which encodes a subunit of the exocyst complex, and rheumatoid arthritis in a Japanese population. Arthritis Rheum 52:1371-1380

Harney SM, Meisel C, Sims AM, Woon PY, Wordsworth BP, Brown MA (2005) Genetic and genomic studies of PADI4 in rheumatoid arthritis. Rheumatology (Oxford) 44:869-872 
Harris Jr ED (1990) Rheumatoid arthritis. Pathophysiology and implications for therapy. N Engl J Med 322:1277-1289

Hoppe B, Haupl T, Gruber R, Kiesewetter H, Burmester GR, Salama A, Dorner $T$ (2006) Detailed analysis of the variability of peptidylarginine deiminase type 4 in German patients with rheumatoid arthritis: a case-control study. Arthritis Res Ther 8:R34

Ikari K, Kuwahara M, Nakamura T, Momohara S, Hara M, Yamanaka H, Tomatsu T, Kamatani N (2005) Association between PADI4 and rheumatoid arthritis: a replication study. Arthritis Rheum 52:3054-3057

Ikari K, Momohara S, Inoue E, Tomatsu T, Hara M, Yamanaka H, Kamatani N (2006a) Haplotype analysis revealed no association between the PTPN22 gene and RA in a Japanese population. Rheumatology (Oxford) 45:1345-1348

Ikari K, Momohara S, Nakamura T, Hara M, Yamanaka H, Tomatsu T, Kamatani N (2006b) Supportive evidence for a genetic association of the FCRL3 promoter polymorphism with rheumatoid arthritis. Ann Rheum Dis 65:671-673

Iwamoto T, Ikari K, Nakamura T, Kuwahara M, Toyama Y, Tomatsu T, Momohara S, Kamatani N (2006) Association between PADI4 and rheumatoid arthritis: a meta-analysis. Rheumatology (Oxford) 45:804-807

Kamatani N, Sekine A, Kitamoto T, Iida A, Saito S, Kogame A, Inoue E, Kawamoto M, Harigai M, Nakamura Y (2004) Large-scale single-nucleotide polymorphism (SNP) and haplotype analyses, using dense SNP Maps, of 199 drug-related genes in 752 subjects: the analysis of the association between uncommon SNPs within haplotype blocks and the haplotypes constructed with haplotype-tagging SNPs. Am J Hum Genet 75:190-203

Kang CP, Lee HS, Ju H, Cho H, Kang C, Bae SC (2006) A functional haplotype of the PADI4 gene associated with increased rheumatoid arthritis susceptibility in Koreans. Arthritis Rheum 54:90-96

Kim JJ, Verdu P, Pakstis AJ, Speed WC, Kidd JR, Kidd KK (2005) Use of autosomal loci for clustering individuals and populations of East Asian origin. Hum Genet 117:511-519

Kochi Y, Yamada R, Suzuki A, Harley JB, Shirasawa S, Sawada T, Bae SC, Tokuhiro S, Chang X, Sekine A, Takahashi A, Tsunoda T, Ohnishi Y, Kaufman KM, Kang CP, Kang C, Otsubo S, Yumura W, Mimori A, Koike T, Nakamura Y, Sasazuki T, Yamamoto K (2005) A functional variant in FCRL3, encoding Fc receptor-like 3, is associated with rheumatoid arthritis and several autoimmunities. Nat Genet 37:478-485

Kuwahara M, Ikari K, Momohara S, Nakamura T, Hara M, Yamanaka H, Tomatsu T, Kamatani N (2005) Failure to confirm association between $S L C 22 A 4$ polymorphism and rheumatoid arthritis in a Japanese population. Arthritis Rheum 52:2947-2948

Lee YH, Rho YH, Choi SJ, Ji JD, Song GG (2007) PADI4 polymorphisms and rheumatoid arthritis susceptibility: a metaanalysis. Rheumatol Int 27:827-833

Lohmueller KE, Pearce CL, Pike M, Lander ES, Hirschhorn JN (2003) Meta-analysis of genetic association studies supports a contribution of common variants to susceptibility to common disease. Nat Genet 33:177-182

Martinez A, Valdivia A, Pascual-Salcedo D, Lamas JR, FernandezArquero M, Balsa A, Fernandez-Gutierrez B, de la Concha EG, Urcelay E (2005) PADI4 polymorphisms are not associated with rheumatoid arthritis in the Spanish population. Rheumatology (Oxford) 44:1263-1266

Martinez A, Sanchez E, Valdivia A, Orozco G, Lopez-Nevot MA, Pascual-Salcedo D, Balsa A, Fernandez-Gutierrez B, de la Concha EG, Garcia-Sanchez A, Koeleman BP, Urcelay E, Martin J (2006a) Epistatic interaction between FCRL3 and
NFkappaB1 genes in Spanish patients with rheumatoid arthritis. Ann Rheum Dis 65:1188-1191

Martinez A, Valdivia A, Pascual-Salcedo D, Balsa A, FernandezGutierrez B, de la Concha E, Urcelay E (2006b) Role of SLC22A4, SLC22A5, and RUNX1 genes in rheumatoid arthritis. J Rheumatol 33:842-846

Mori M, Yamada R, Kobayashi K, Kawaida R, Yamamoto K (2005) Ethnic differences in allele frequency of autoimmune-diseaseassociated SNPs. J Hum Genet 50:264-266

Newman B, Wintle RF, van Oene M, Yazdanpanah M, Owen J, Johnson B, Gu X, Amos CI, Keystone E, Rubin LA, Siminovitch KA (2005) SLC22A4 polymorphisms implicated in rheumatoid arthritis and Crohn's disease are not associated with rheumatoid arthritis in a Canadian Caucasian population. Arthritis Rheum 52:425-429

Newman WG, Zhang Q, Liu X, Walker E, Ternan H, Owen J, Johnson B, Greer W, Mosher DP, Maksymowych WP, Bykerk VP, Keystone EC, Amos CI, Siminovitch KA (2006) Rheumatoid arthritis association with the FCRL3 $-169 \mathrm{C}$ polymorphism is restricted to PTPN22 1858T-homozygous individuals in a Canadian population. Arthritis Rheum 54:3820-3827

Orozco G, Sanchez E, Gonzalez-Gay MA, Lopez-Nevot MA, Torres B, Pascual-Salcedo D, Balsa A, Pablos JL, Garcia A, GonzalezEscribano MF, Martin J (2006) SLC22A4, RUNX1, and SUMO4 polymorphisms are not associated with rheumatoid arthritis: a case-control study in a Spanish population. J Rheumatol 33:1235-1239

Plenge RM, Padyukov L, Remmers EF, Purcell S, Lee AT, Karlson EW, Wolfe F, Kastner DL, Alfredsson L, Altshuler D, Gregersen PK, Klareskog L, Rioux JD (2005) Replication of putative candidate-gene associations with rheumatoid arthritis in $>4,000$ samples from North America and Sweden: association of susceptibility with PTPN22, CTLA4, and PADI4. Am J Hum Genet 77:1044-1060

Reveille JD (1998) The genetic contribution to the pathogenesis of rheumatoid arthritis. Curr Opin Rheumatol 10:187-200

Sasieni PD (1997) From genotypes to genes: doubling the sample size. Biometrics 53:1253-1261

Suzuki A, Yamada R, Chang X, Tokuhiro S, Sawada T, Suzuki M, Nagasaki M, Nakayama-Hamada M, Kawaida R, Ono M, Ohtsuki M, Furukawa H, Yoshino S, Yukioka M, Tohma S, Matsubara T, Wakitani S, Teshima R, Nishioka Y, Sekine A, Iida A, Takahashi A, Tsunoda T, Nakamura Y, Yamamoto K (2003) Functional haplotypes of PADI4, encoding citrullinating enzyme peptidylarginine deiminase 4 , are associated with rheumatoid arthritis. Nat Genet 34:395-402

Takata Y, Hamada D, Miyatake K, Nakano S, Shinomiya F, Scafe CR, Reeve VM, Osabe D, Moritani M, Kunika K, Kamatani N, Inoue H, Yasui N, Itakura M (2007) Genetic association between the $P R K C H$ gene encoding protein kinase Ceta isozyme and rheumatoid arthritis in the Japanese population. Arthritis Rheum 56:30-42

Thabet MM, Wesoly J, Slagboom PE, Toes RE, Huizinga TW (2007) FCRL3 promoter $169 \mathrm{CC}$ homozygosity is associated with susceptibility to rheumatoid arthritis in Dutch Caucasians. Ann Rheum Dis 66:803-806

Tokuhiro S, Yamada R, Chang X, Suzuki A, Kochi Y, Sawada T, Suzuki M, Nagasaki M, Ohtsuki M, Ono M, Furukawa H, Nagashima M, Yoshino S, Mabuchi A, Sekine A, Saito S, Takahashi A, Tsunoda T, Nakamura Y, Yamamoto K (2003) An intronic SNP in a RUNX1 binding site of SLC22A4, encoding an organic cation transporter, is associated with rheumatoid arthritis. Nat Genet 35:341-348

Wigginton JE, Cutler DJ, Abecasis GR (2005) A note on exact tests of Hardy-Weinberg equilibrium. Am J Hum Genet 76:887-893 